\title{
Cubiertas planas fitodepuradoras Propuesta de gestión de aguas grises en altura
} Phytodepuration flat roofs Proposal of grey water management

\author{
A. Gómez-González ${ }^{(*)}$, M. Chanampa ${ }^{(*)}$, I. Morgado ${ }^{(*)}$, C. Acha ${ }^{(*)}$, C. Bedoya ${ }^{(*)}$, J. Neila ${ }^{(*)}$
}

RESUMEN

El trabajo se presenta con el objetivo de evaluar los beneficios de la incorporación de nuevas estrategias de gestión de agua en el medio urbano. Para ello se han tenido en cuenta los condicionantes urbanos y los hábitos de consumo de agua en las ciudades españolas de tamaño medio. A través del aprovechamiento de las amplias superficies de cubierta plana existente en las áreas de media densidad, se plantea la incorporación de sistemas industrializados de fitodepuración, que permitan tanto la reducción del consumo de agua potable, como la disminución del volumen vertido a las redes de saneamiento. Los resultados de la investigación demuestran que el consumo de agua potable en usos que no lo requieren representa más del $30 \%$ del volumen total utilizado en usos domésticos, por un ciudadano medio. Mediante la aplicación de la propuesta planteada, es posible alcanzar ahorros de hasta el 59\% respecto al modelo actual.

$113-117$

Palabras clave: reutilización aguas grises, gestión urbana, fitodepuración, cubiertas verdes.

\section{SUMMARY}

The present research aims to evaluate the benefits of new urban water management strategies. In this sense, the urban conditions and the water consume habits of medium sized Spanish cities have been studied. Through the use of the large flat roof surfaces existing in medium density areas, it is possible to include industrialized phytodepuration systems which reduce the drinkable water consume and diminish the volume of waste water that is daily discharged to the sewerage network. The research shows that more than $30 \%$ of potable water is being used in domestic uses that doesn't require this quality. The use of the proposal can reach savings up to $59 \%$ in comparison with the current water management model.

Keywords: grey water reuse, phytodepuration, urban water management, green roofs. 


\section{INTRODUCCIÓN}

El crecimiento demográfico del medio urbano, asociado a los nuevos modelos de comportamiento social frente al agua, está propiciando un aumento considerable del consumo de este recurso.

Por ello, se considera necesaria una revisión, no sólo de los hábitos de conducta, sino también de los modelos de planeamiento urbano, de las metodologías proyectuales y de la integración de mecanismos que, desde la fase de diseño, favorezcan un aprovechamiento óptimo de los recursos hídricos.

\subsection{Contexto de la Investigación}

El trabajo que se presenta se enmarca dentro del subproyecto 10 -Sistemas para la Optimización del Comportamiento Eficiente de las Viviendas-, dentro del Proyecto Singular Estratégico INVISO (Industrialización de Viviendas Sostenibles), desarrollado durante los años 2007-2010 y financiado por el Ministerio de Ciencia e Innovación del Gobierno de España.

El objetivo principal de la línea de gestión del agua ha sido el desarrollo de nuevos sistemas industrializados, que permitan la optimización de los recursos hídricos en vivienda; haciendo especial énfasis en aquellas medidas que consigan una redefinición de los hábitos domésticos asociados al agua.

\section{METODOLOGÍA}

La metodología de investigación se plantea desde el estudio y evaluación de medidas y sistemas que favorezcan una correcta gestión integral del ciclo del agua, especialmente sobre el área de influencia del medio urbano.

El trabajo se organiza desde diferentes escalas de intervención, permitiendo la actuación sobre los hábitos de conducta del usuario, la incorporación de medidas de diseño arquitectónicas y la integración de sistemas de gestión urbana. Para ello, el proyecto se ha organizado en cuatro fases principales, que permitan establecer aquellos ámbitos en los que es posible implementar nuevas estrategias de actuación y mejora de las situaciones actuales. Las fases principales son:

\subsection{Determinación del estado actual de los sistemas de gestión de agua y catalogación de las estrategias}

Se han analizado un total de 166 diferentes estrategias, correspondientes a los siguientes ámbitos: reutilización de agua de Iluvia, reducción del consumo, optimización de sistemas de riego, depuración y disminución de evaporación en piscinas, reutilización de aguas grises, depuración de aguas residuales y sistemas de calidad del agua.

\subsection{Baremación ponderada y selección de estrategias a desarrollar}

Cada estrategia ha sido descrita a través de parámetros gráficos y analíticos, definiendo sus niveles de sostenibilidad, innovación y funcionalidad, con el objetivo de proceder, posteriormente, a su baremación ponderada.

La comparación de estrategias, respecto a los niveles anteriores, ha determinado que los tratamientos de aguas grises son los que poseen un mayor potencial de innovación en relación con los parámetros descritos. Mediante su desarrollo, es posible alcanzar importantes ahorros de consumo de agua doméstica potable, al mismo tiempo que la mejora de su diseño puede favorecer una fácil integración en tipologías edificatorias residenciales.

\subsection{Desarrollo de un sistema industrializado de fitodepuración en cubierta}

Entre las estrategias estudiadas, se ha observado que, aunque los sistemas de fitodepuración necesitan habitualmente grandes superficies de tratamiento del agua, es posible la optimización de sus dimensiones, para adaptar sus beneficios a prototipos industrializados y modulares, que puedan ser aplicados en cubiertas o jardines urbanos.

Concretamente, la investigación se ha centrado en la definición de un sistema versátil, que pueda reutilizar las amplias superficies de cubierta plana actualmente infrautilizadas en contextos urbanos.

\subsection{Evaluación de reducción de consumos y análisis de resultados}

Se ha procedido a la evaluación analítica de la capacidad de integración y reducción de consumos que el sistema propuesto plantea. Para ello, se ha localizado un área potencial de aplicación, en una zona residencial urbana característica de media densidad, donde se han estudiado los condicionantes urbanos, los hábitos de consumo y la posibilidad de integración del prototipo planteado.

En paralelo, se está construyendo un prototipo de cubierta plana en una vivienda demostrador en Tembleque (Toledo), cuya puesta en funcionamiento está prevista en otoño de 2011. A partir de su monitorización se establecerán los ahorros reales de agua, así como su calidad una vez depurada; los cuales serán comparados con los resultados 
del estudio expuesto en el presente artículo. Además, un primer prototipo de similares características ha sido construido a cota de jardín, por el biólogo Óscar Domínguez, en el Aula de Educación Medioambiental de Pozuelo de Alarcón (Madrid).

\section{ESTADO DE LA CUESTIÓN}

\subsection{Consumos domésticos medios de agua}

Según datos del Instituto Nacional de Estadística, el consumo medio doméstico de agua potable en España es de 167 litros. El valor más representativo se produce en lavabos y duchas, siendo de 60 litros/persona (INE 2005), mientras que la descarga de inodoros requiere una media diaria de 45 litros/ persona (INE 2005), lo que prácticamente equipara ambos valores (figura 1). Además, si se incluye el agua de lavadoras, el aporte diario a la red de saneamiento, respecto a estas fuentes, se incrementa hasta los 138 litros/persona.

Teniendo en cuenta las discontinuidades de los regímenes pluviométricos de las regiones mediterráneas, y que la utilización de algunos usos domésticos no requiere el uso de agua potable (inodoros, riego, mantenimiento urbano, etc.), los valores de consumo actuales justifican la necesidad del tratamiento de las aguas grises para potenciar su reutilización.

\subsection{Reutilización de aguas grises}

Respecto a la definición de aguas grises, no existe todavía un consenso, a la hora de catalogarlas en función de las fuentes que las producen. Mientras algunos autores las definen como todas aquellas utilizadas en el ámbito doméstico, excluyendo las empleadas para la descarga de inodoros, lo que incluye las procedentes de la higiene personal, lavadoras, lavavajillas y sumideros de cocinas (1), otros consideran solamente las de lavabo, ducha/ bañera, bidet y en ocasiones lavadora (2).

En caso de plantear la reutilización conforme a la primera situación, el agua procedente de cocinas aumentaría considerablemente los niveles de Demanda Biológica de Oxígeno (DBO) y fósforo, igualándolos en algunos casos a las cargas de inodoros (3). Además, esta hipótesis incrementaría considerablemente la red separativa de recogida de aguas grises a instalar, dificultaría el control de vertidos de productos químicos por desagües, aumentaría la cantidad de sólidos en suspensión y su dificultad de filtrado, mientras que la diferencia de volumen de agua potencialmente reutilizable, respecto con la segunda opción, no alcanzaría el 17\%. Por esta razón, y teniendo en cuenta también los límites económicos y constructivos de las intervenciones en rehabilitación urbana, se recogerán únicamente para su tratamiento las aguas procedentes de lavabo, bañera/ducha, bidé y lavadora.

Aunque al evitar la captación de desagües de cocina se reduce considerablemente la carga contaminante, se debe tener en cuenta que uno de los principales problemas de las aguas grises es la elevada fluctuación de los niveles de Demanda Biológica de Oxígeno (DBO) y de Demanda Química de Oxígeno (DQO), principalmente a causa de las diferencias de hábitos de conducta de cada usuario y el incremento considerable en los casos de existencia de niños en la vivienda (1).
1. Principales consumos domésticos de agua potable. Elaboración propia.

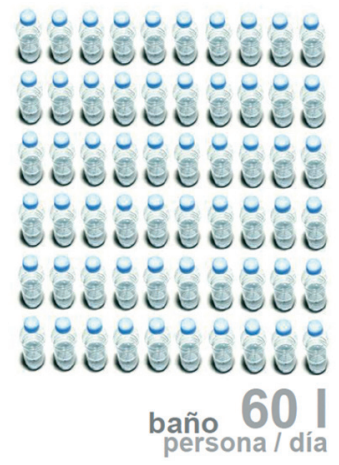

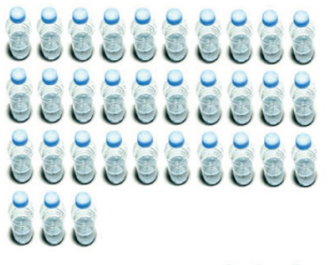
lavadora 33 .

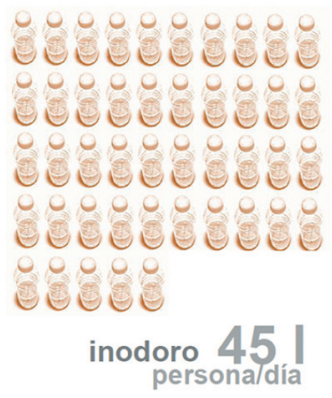

La siguiente tabla 1 expresa los consumos medios de agua potable por persona y día en vivienda (Instituto Nacional de Estadística), comparándolos con los consumos estimados por la Fundación Ecología y Desarrollo, en el caso de aplicación de sencillas medidas correctoras a escala doméstica (inodoros de baja descarga, grifería con aireadores, etc.)

Tabla 1

Comparativa de consumos totales de agua

\begin{tabular}{|l|c|c|}
\cline { 2 - 3 } \multicolumn{1}{c|}{} & $\begin{array}{c}\text { Consumo } \\
\text { (I/per día) } \\
\text { (INE 2005) }\end{array}$ & $\begin{array}{c}\text { Consumo } \\
\text { (I/per día) } \\
\text { (ECODES) }\end{array}$ \\
\hline $\begin{array}{l}\text { Ducha/bañera, } \\
\text { lavabo y bidé }\end{array}$ & $\mathbf{6 0}$ & $\mathbf{4 6}$ \\
\hline $\begin{array}{l}\text { Descarga de } \\
\text { inodoros }\end{array}$ & 45 & 16 \\
\hline Lavadora & $\mathbf{3 3}$ & $\mathbf{1 8}$ \\
\hline Cocina y bebida & 19 & 13 \\
\hline Limpieza & 10 & 7 \\
\hline $\begin{array}{l}\text { Total producción } \\
\text { aguas grises }\end{array}$ & $\mathbf{9 3}$ & $\mathbf{6 4}$ \\
\hline
\end{tabular}

Datos del Instituto Nacional de Estadística (INE) del 2005, y de la Fundación Ecología y Desarrollo (ECODES) resultado de la aplicación de estrategias de ahorro.

Fuente: Elaboración propia. 


\subsection{Fitodepuración}

Como medida de tratamiento para la reutilización de las aguas grises, se ha estudiado la optimización de los sistemas de fitodepuración, enfocados a su adaptación en entornos urbanos construidos.

La fitodepuración consiste en la limpieza de agua contaminada mediante procesos biológicos, desarrollados principalmente en la masa rizomática de plantaciones acuáticas (4).

Estas plantas se caracterizan por desarrollar mecanismos de adaptación en medios con amplia disponibilidad hídrica pero pobres en oxígeno, por lo que presentan epidermis muy delgadas que reducen la resistencia al paso de gases, agua y nutrientes, y estructuras de canales aeríferos formados por tejidos con un gran desarrollo de espacios intercelulares, a través de los cuales circula y se almacena el oxígeno del aire.

Esta configuración facilita la difusión de gases entre los diferentes órganos de la planta y la transferencia de oxígeno desde los órganos fotosintéticos exteriores hacia las raíces, contribuyendo a la oxigenación del agua y al desarrollo de colonias de bacterias aerobias de la rizosfera (4). Éstas son las responsables de los procesos de oxidación de sustancias orgánicas, de amonificación, nitrificación y de-nitrificación de los componentes del agua; de modo que una vez descompuestos, serán absorbidos por la planta a través de su masa rizomática. A su vez, los microorganismos existentes extraen la energía de las sustancias orgánicas presentes y usan las sales nutritivas disueltas para su propio desarrollo, de modo que su existencia supone el control frente a la proliferación excesiva de otros microorganismos y virus patógenos. Se debe tener en cuenta que en el caso de reutilización de aguas grises, las concentraciones son bastante inferiores respecto a las aguas residuales, por lo que la depuración será más rápida.

Los primeros sistemas de tratamiento a través de fitodepuración mediante bancales (Reed bed treatment systems-RBTS) fueron investigados por primera vez en 1960 en Alemania, por Siedel and Kickuth (6). Estos sistemas están basados en la eliminación de contaminantes del agua a su paso por amplios canales de arena o grava, donde se enraízan las plantaciones acuáticas, fundamentándose en el principio de desarrollo de bacterias aerobias alrededor de la masa rizomática. Tras una fase de desbaste y filtrado, se utilizan comúnmente como tratamiento secundario o terciario de aguas residuales. Entre los diferentes sistemas existentes, destacan los de flujo horizontal superficial y subsuperficial, de modo que la construcción de bancales logra unos rendimientos por área construida hasta 100 veces mayores que los sistemas de lagunaje tradicionales (7).

Sin embargo, a pesar de su elevada efectividad, cercana a una eliminación de DBO y DQO del $80-90 \%$ (7), los principales problemas de estos sistemas para su aplicación en medios urbanos de alta y media densidad, derivan de su todavía elevada superficie necesaria. Además, al encontrarse en un medio poroso de arena o grava, su peso en cubierta incrementa y el crecimiento de las raíces, acaba colmatando el sustrato, dificultando su mantenimiento.

De este modo, mientras los sistemas tradicionales se fundamentan en cuatro componentes principales: Vegetación, flujo de agua, sustrato y poblaciones microbiológicas albergadas en la masa rizomática, la estrategia desarrollada propone la eliminación del sustrato mediante la utilización de la técnica de macrofitas en flotación, para de este modo aumentar la superficie de contacto de raíces y bacterias con el agua.

La técnica de macrofitas en flotación, desarrollada por el Grupo de Investigación de Agroenergética de la Universidad Politécnica de Madrid y dirigido por el Catedrático Jesús Fernández, se caracteriza por el empleo de higrófitos que se extrapolan de su medio habitual a un medio acuático, aprovechando el gran volumen rizomático que desarrollan en sus primeras fases de crecimiento en el terreno. La innovación respecto a este sistema, construido tradicionalmente in situ y utilizado para grandes superficies como el caso de Lorca (4), consiste en la optimización del recorrido del agua y la industrialización de los bancales para reducir su ancho, aumentar el contacto entre las bacterias de la masa rizomática y el agua, y de este modo disminuir la superficie necesaria, aumentando el volumen de depuración y disminuyendo su peso para su aplicación en cubierta.

\section{CONDICIONANTES DE LOS MEDIOS URBANOS DE MEDIA DENSIDAD}

\subsection{Distribución demográfica en España}

La distribución de la población en España difiere de la mayoría de los países de Europa Occidental, principalmente de aquellos donde los sistemas de fitodepuración han presentado un mayor desarrollo, como son las Islas Británicas y centro Europa. La densidad de población en España es de unos 91,4 hab/km², mientras la de otros países de dimensiones similares como Alemania, alcanza los $250 \mathrm{hab} / \mathrm{km}^{2}$ o Reino Unido los $243 \mathrm{hab} / \mathrm{km}^{2}$. 
Sin embargo, la población española se caracteriza por su concentración en ciudades de tamaño mediano o grande, distribuida en áreas metropolitanas costeras y zonas de valle densamente pobladas.

\section{2. Área metropolitana de Madrid}

El área metropolitana de Madrid constituye la cuarta más grande de la Unión Europea, después de Londres, Duisburg y París. Su desarrollo a partir de los años 1960, provocó el crecimiento de las ciudades periféricas, mediante un modelo de alta y media densidad, propiciado por la construcción de bloques en altura y la carencia de zonas verdes.

Respecto a la gestión del agua, este modelo de crecimiento fomentó la construcción de Estaciones Depuradoras de Aguas Residuales (E.D.A.R.), en zonas inicialmente aisladas, donde se depurarían las aguas residuales de todos los habitantes del núcleo urbano.

Con el tiempo, estas instalaciones se han visto desbordadas, mientras que el desarrollo urbanístico las ha vuelto a incorporar de nuevo a las áreas urbanas construidas (figura 2). El principal problema de estas instalaciones es su saturación, como consecuencia de la falta de separación entre aguas grises, residuales y pluviales, lo que reduciría considerablemente el volumen de agua a tratar. Además, la progresiva impermeabilización de los suelos urbanos favorece que en periodos de lluvias las EDAR reciban un volumen de aguas contaminadas, mayor del que pueden depurar.

Por esta razón, se considera que la intervención en el ciclo urbano del agua es indispensable para una correcta gestión de este recurso, evitando el sobredimensionamiento innecesario de los equipamientos de depuración. La incorporación de estaciones de tratamiento de aguas grises a escalas de distrito, contribuirá en gran medida a la reducción de los consumos de agua potable en usos que no lo requieren, al mismo tiempo que permitirá aumentar la eficacia de las instalaciones de tratamiento de aguas a nivel global (figura 3).

Por ello, se ha realizado el estudio de los espacios de oportunidad de las ciudades de alta y media densidad, donde a través de la rehabilitación urbana se reaprovechen las áreas de cubierta para la localización de instalaciones controladas de fitodepuración. De este modo, el beneficio no estará asociado únicamente a la reducción de consumo de agua, sino también a los efectos positivos del comportamiento higrotérmico que las cubiertas aljibe presentan y a las ventajas que la naturalización arquitectónica supone para los habitantes de las ciudades contemporáneas.

\subsection{Caso de estudio}

Se ha seleccionado como caso de estudio, un conjunto de viviendas situadas en el área metropolitana de Madrid, concretamente en la ciudad de Alcalá de Henares. La densidad de la zona y la localización de amplias áreas de cubierta plana sobre sector terciario, ha determinado la elección del lugar como ejemplo tipo de actuación.

La zona de intervención es la formada por las 2 manzanas delimitadas por la vía Complutense con las calles Ribera, Murillo, Caballería Española, Juan de Arellano y Avda. Manuel Azaña. Se construyó a finales de la década de 1970, y está compuesta por dos grandes bloques en forma de $U$ enfrentados, entre los cuales se sitúa un volumen de uso terciario (figura 4). El edificio de viviendas tiene siete plantas más bajo comercial y una planta sótano de instalaciones y almacenes comerciales; mientras que en la zona central de la manzana se encuentra una planta de aparcamiento subterráneo.

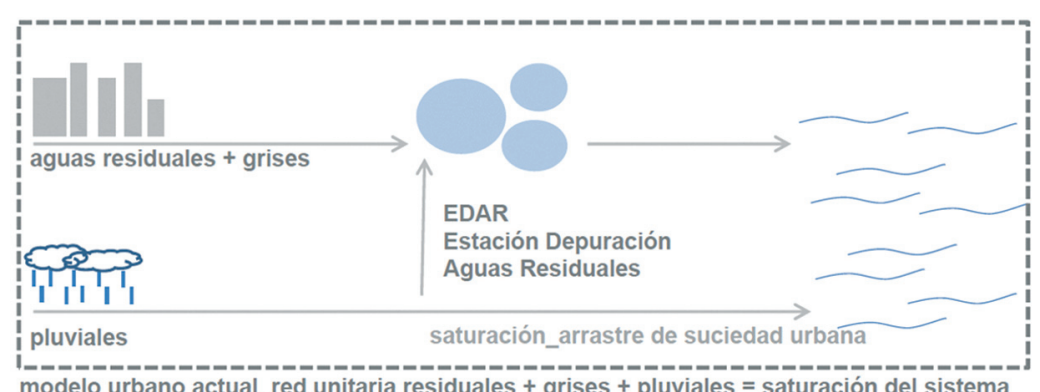

modelo urbano actual_red unitaria residuales + grises + pluviales = saturación del sistema

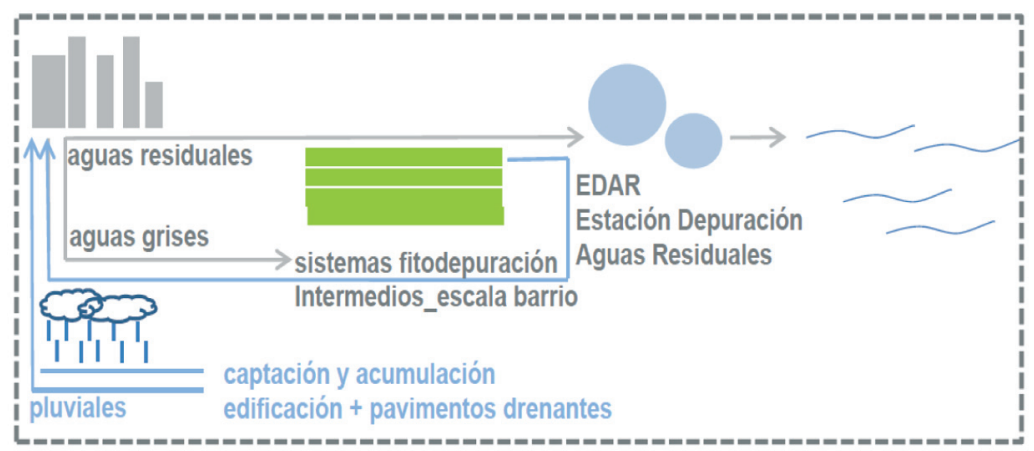

propuesta_red separativa residuales+grises $/$ acumulación pluviales = disminución consumo

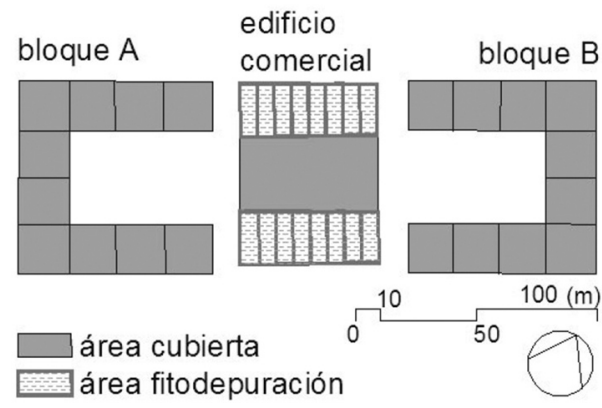

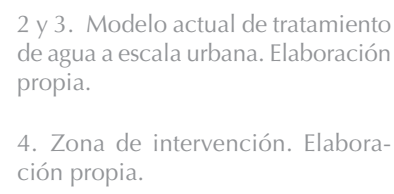
ción propia. 
5. Vistas del área de propuesta. Elaboración propia.

6. Principio de funcionamiento. Elaboración propia.
Las viviendas tienen una superficie media construida de 100 a $130 \mathrm{~m}^{2}$, cuatro habitaciones y dos baños; lo que determina una media de 3 habitantes equivalentes por vivienda para el cálculo de producción de aguas grises.

El conjunto de viviendas está formado por 10 portales por manzana, y 4 viviendas por portal, lo que hacen un total de 280 viviendas. Teniendo en cuenta los dos bloques, el número de habitantes equivalentes total a considerar es de 1.680 .

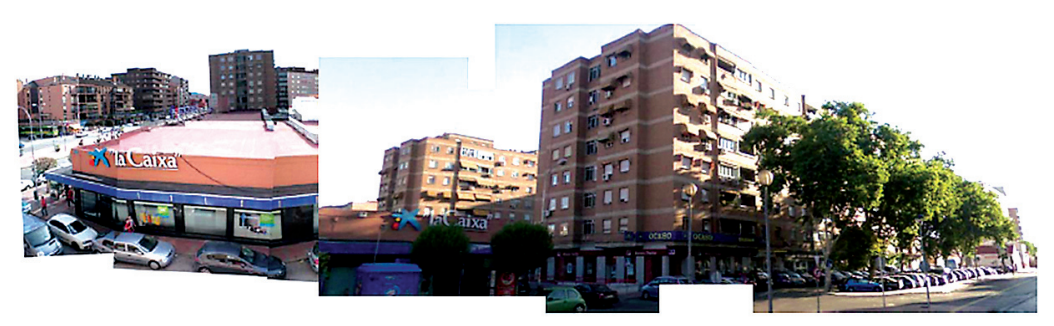

Por otro lado, el bloque de uso terciario está dedicado a comercio y distribuido en una sola planta sobre otra de aparcamiento subterráneo. Su cubierta plana (figura 5), se presenta como un área de oportunidad para la reinterpretación de nuevos usos, ya que la mayor parte de los $4.690 \mathrm{~m}^{2}$ se encuentra libre, a excepción de dos pequeñas edificaciones de una planta y las instalaciones de la zona comercial que se sitúa debajo.

\section{ESTRATEGIA DE INTERVENCIÓN}

Con el objetivo de evaluar analíticamente el impacto del prototipo propuesto, se ha estudiado la intervención sobre la cubierta plana del núcleo de equipamientos, aprovechando su alto porcentaje de superficie libre (figura 6). De este modo se consigue un área de actuación en la que el ciudadano no tiene contacto directo con la zona de tratamiento, al mismo tiempo que se proporciona a las viviendas de toda la zona la visión de un nuevo jardín urbano.

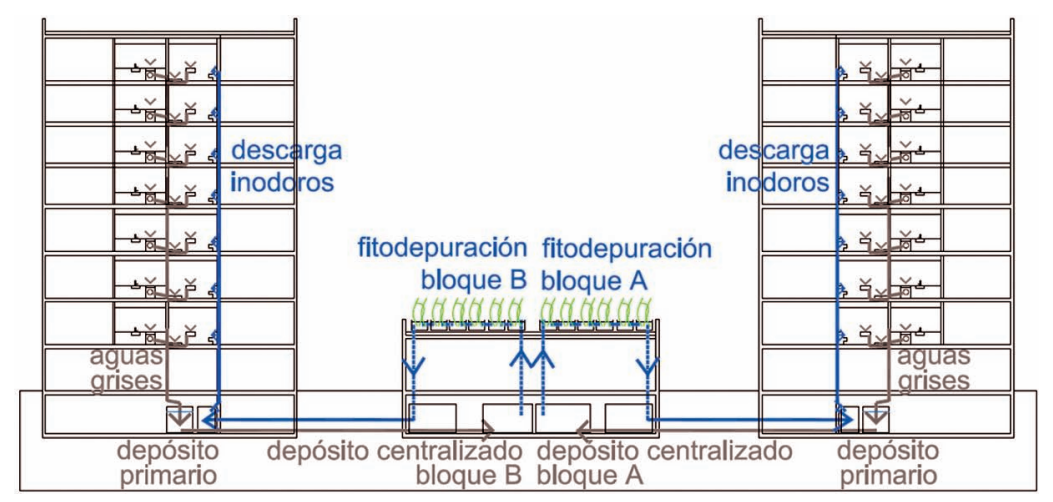

La estrategia propuesta se basa en un sistema centralizado de recogida y tratamiento basado en el siguiente funcionamiento: Las aguas grises de cada vivienda, procedentes de ducha/bañera, bidé, lavabo y lavadora, son recogidas por una red separativa. Se hacen pasar por un prefiltro para la eliminación de grasas y sólidos en suspensión y se acumulan en un depósito primario, uno por portal. Desde ahí serán bombeadas cada 24 horas al sistema centralizado secundario. Las aguas recogidas en este depósito, son impulsadas a la zona de bancales de fitodepuración, dimensionada para asegurar el tratamiento de todas las aguas que por ahí circulen, durante un periodo mínimo de 7 días. Una vez depurada, el agua será de nuevo almacenada, para reutilizarse en descarga de inodoros, en riego por goteo subterráneo de las zonas verdes adyacentes y en baldeo de calles.

La situación de los baños de la vivienda, agrupados de modo que comparten tabique de instalaciones, favorece significativamente la reducción de obra en el interior y los costes del trazado de la nueva red; al igual que la de impulsión para descarga de inodoros.

\section{COMPONENTES DEL SISTEMA}

A continuación se exponen los componentes principales del sistema. El orden de exposición está en correlación con el ciclo que el agua va realizando durante el proceso de captación y recogida, tratamiento de fitodepuración y posterior almacenaje.

\subsection{Red separativa}

La primera intervención sobre el parque existente de viviendas, consiste en realizar una red separativa de aguas grises que recoja el agua procedente de duchas/bañeras, bidés, lavabos y lavadoras, mediante un sistema centralizado que canalice el flujo de varias viviendas al depósito primario de acumulación. En el caso de estudio, la agrupación de núcleos húmedos dispuestos de modo contiguo, favorece en gran medida el trazado de la red, disminuyendo el impacto de la obra necesaria y el coste de la misma.

Respecto a la red separativa de cada baño, se recomienda la incorporación de sifones individuales en todos los aparatos, frente a la solución tradicional de bote sifónico. De este modo se evitan servidumbres con viviendas inferiores, se optimiza el espacio y se minimiza la apertura de rozas en tabiques y perforaciones en forjado. Además, la aplicación de sifones individuales acorta la distancia del cierre hidráulico al desagüe del aparato, disminuyendo la probabilidad de atascos y malos olores. 


\subsection{Filtración}

En el caso de estudio, se propone el filtrado y separación de grasas y sólidos de modo individualizado por portales. Las bajantes principales de las cuatro redes separativas de cada portal confluyen en una trampa de grasas centralizada, donde se decantarán los sólidos por peso en su parte inferior, y las grasas y parte de jabones no disueltos flotarán en su superficie. La ventaja del caso de estudio, reside en el mantenimiento del sistema; ya que el mismo personal se encargará del cuidado periódico del buen funcionamiento de las instalaciones de los 20 portales existentes en la intervención.

\subsection{Depósito primario de acumulación de aguas grises}

Las aguas grises prefiltradas procedentes de la trampa de grasas, son acumuladas en un primer tanque de almacenamiento, situado en la zona de instalaciones que cada portal dispone. El tanque incorpora un sistema regulador de volumen, tipo boya y un indicador de nivel. De este modo se evitará tanto el desbordamiento como la falta de volumen de agua. Además, se dispondrá una derivación de aguas grises a la red de saneamiento en caso de que la producción sea mayor que el volumen del tanque; y a su vez se proveerá de una toma de agua que permita el mantenimiento de un volumen mínimo.

Para evitar el desarrollo de bacterias, las aguas grises prefiltradas permanecerán un máximo de 24 horas en el depósito primario de acumulación. Además, debido a su situación en sótanos, se muestra protegido de las altas temperaturas, con una temperatura baja y relativamente constante. Cada uno de los depósitos primarios, contará con una bomba sumergible que impulsará periódicamente las aguas prefiltradas al sistema centralizado de acumulación. Es necesario que la bomba elegida pueda funcionar en seco sin riesgos de deterioro en caso de avería de la red de abastecimiento de aguas grises.

\subsection{Depósitos centralizados de acumulación de aguas grises}

El agua que ha sido impulsada por cada uno de los portales, es recogida en dos depósitos, uno por manzana, desde el que se impulsará a los bancales de fitodepuración situados en cubierta.

Teniendo en cuenta que el agua es impulsada a diario, el número total de habitantes equivalentes para el conjunto de las dos manzanas es de 1.680, y el consumo medio diario por persona es de 93 litros. Si no existieran los depósitos primarios, el tanque centralizado tendría que tener un volumen de 156,240 $\mathrm{m}^{3}$. Sin embargo, la existencia de tanques individualizados por portales, permite el control del agua que llega al tanque centralizado, de modo que se van alternando las impulsiones a éste periódicamente.

El número de portales por manzana es de 10 , lo que permite que cada portal acumule las aguas de 28 viviendas durante 24 horas, y las impulse al depósito centralizado correspondiente con un desfase de dos horas, respecto del portal contiguo. De este modo, cada segundo depósito servirá de receptor de las aguas provenientes cada una de las manzanas, y desde el se impulsarán las aguas recibidas a los bancales de fitodepuración; que se organizarán en dos circuitos independientes, uno por manzana. El sistema de organización permite la reducción de cada tanque hasta unas dimensiones de $7 \mathrm{~m}^{3}$.

\subsection{Red de impulsión de aguas grises a bancales}

El agua de cada uno de los depósitos centralizados será impulsada a cada sistema de bancales correspondiente en cubierta. Para la definición de la red de impulsión se tendrá en cuenta que parte de su recorrido transcurre por el exterior de la edificación. Debiéndose proteger de los agentes atmosféricos, de posibles ataques de roedores y de manera especial de la radiación ultravioleta.

\subsection{Bancales prefabricados}

Las aguas grises son derivadas a los bancales prefabricados donde se procederá a su fitodepuración (figuras 7 y 8). Cada bancal se organiza en tres espacios diferenciados para un mejor filtrado y una minimización de las interferencias que la masa rizomática pueda ejercer sobre las canalizaciones entre bancales. Para ello, cada unidad se subdivide en dos pequeñas zonas a los extremos, separadas del espacio central mediante un filtro de malla metálica inoxidable.

Las dimensiones modulares y el planteamiento de crecimiento del sistema por agregación de bancales, facilitan la puesta en obra y el transporte de piezas de tamaño medio. Además, se consigue la adaptación a diferentes casuísticas en función de las necesidades de cada edificación. La modulación de los bancales, formando un circuito que determina el recorrido del agua, permite optimizar el contacto de las aguas grises con las raíces de las plantaciones acuáticas, donde se desarrollan las bacterias aerobias responsables de la fitodepuración.

Los bancales son de PRFV y para favorecer su comportamiento mecánico, cuentan con 


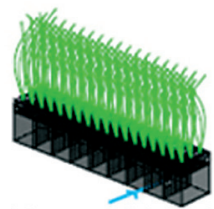

sistema prefabricado en PRFV
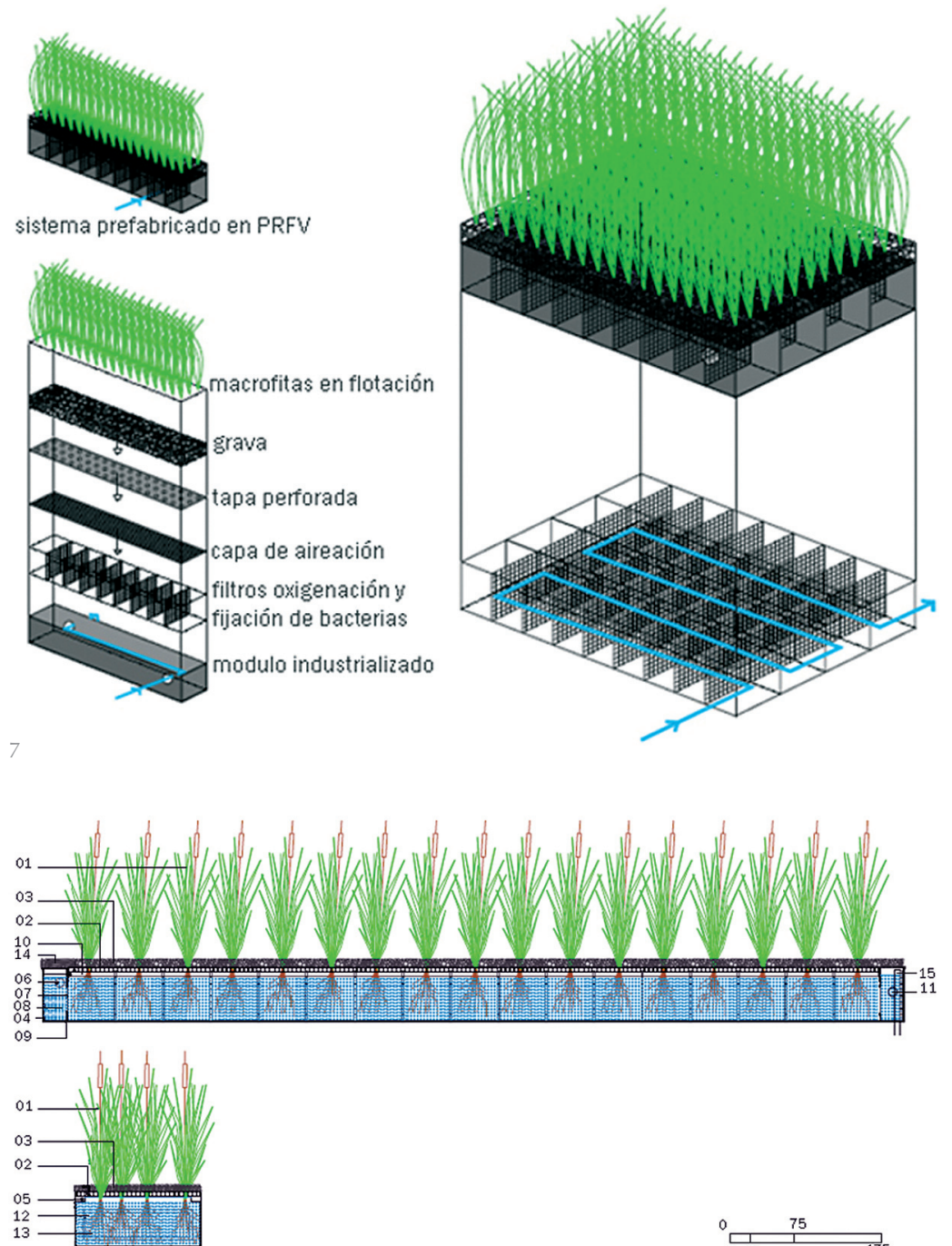

8

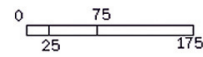

refuerzos transversales de atado y con la plataforma de sujeción de macrofitas. Su tamaño será de $10 \times 1,5 \mathrm{~m}$; previendo su adaptación dimensional a los sistemas de transporte y la relativa facilidad de reparación y/o sustitución de elementos modulares, pudiendo establecer conexiones intermedias temporales entre bancales.

La plataforma, contribuye a la sujeción de las plantaciones acuáticas y a la estabilidad del sistema, y además permite la creación de una cámara de aire entre la lámina de agua superior y la capa de grava, lo que permite la aireación y reducción de emisión de olores. Ese espacio sirve además de zona de seguridad frente al desbordamiento en caso de lluvia; situación que se ve a su vez complementada con la incorporación puntual de sumideros de regulación en los bancales intermedios. De este modo, en situaciones de grandes Iluvias o periodos prolongados, los rebosaderos permitirán recoger el agua excedente en una red separativa que derive a un aljibe secundario; pudiendo volver a ser impulsada al sistema, cuando las precipitaciones cesen y el volumen total pueda reequilibrarse.

El tiempo necesario para una correcta depuración son 7 días (4), transcurridos los cuales el agua es expulsada y almacenada en depósitos modulares, para su posterior reutilización. La construcción modular del sistema permite su crecimiento en superficie, por agregación de bancales, de acuerdo con la demanda existente; de modo que si bien en el presente artículo se ha estudiado un caso concreto, su extrapolación es posible a otras situaciones.

\subsection{Sistema de acumulación de aguas tratadas}

La circulación del agua en los bancales se realiza mediante sistema de pistones, de modo que al añadir a diario el nuevo caudal, el primer módulo se desborda hacia el segundo, y así sucesivamente. El agua depurada, es desbordada al depósito de acumulación, desde el que se suministrará agua a cada portal para descarga en inodoros, y el agua restante servirá de apoyo para riego por goteo subterráneo.

\subsection{Refuerzo estructural}

La relación entre la superficie del sistema propuesto y el número de habitantes es relativamente baja, de modo que para una vivienda unifamiliar sería necesaria un área inferior a $3 \mathrm{~m}^{2}$ en la cubierta.

Sin embargo, para el caso estudiado, al concentrar todo el área de fitodepuración sobre una cubierta existente y dar servicio a 1.680 habitantes equivalentes, la estructura debería reforzarse en la zona de bancales, para una sobrecarga extra mínima de $600 \mathrm{~kg} / \mathrm{m}^{2}$.

\section{SELECCIÓN DE ESPECIES}

La selección de propuestas se ha realizado, teniendo en cuenta la climatología continental de inviernos y veranos rigurosos de la zona de propuesta (tabla 2).

A su vez, la situación en cubierta, optimiza la captación de la radiación solar y favorece los procesos de fotosíntesis. Se ha estimado que con una proporción de 10 plantaciones por $\mathrm{m}^{2}$, se colocarían unas 15.300 plantas necesarias para optimizar el sistema de tratamiento.

Respecto a la longitud de raíces, se han seleccionado las especies que se muestran en la siguiente tabla y que presentan tanto un buen comportamiento en las condiciones climáticas del centro peninsular, como un 
crecimiento de raíces adaptable a los $50 \mathrm{~cm}$ de profundidad de agua de los bancales (5).

En cuanto al mantenimiento del sistema, tanto el diseño industrializado de los bancales y la inclusión de áreas protegidas, como la selección de especies, disminuyen considerablemente los requerimientos. Con una poda realizada dos veces al año, es suficiente para el crecimiento correcto de las plantaciones. Además, los excedentes cortados pueden ser reutilizados mediante procesos de compostaje.

\section{CUANTIFICACIÓN DE RESULTADOS}

\subsection{Optimización de sistemas extensivos en flotación}

En la siguiente tabla, se muestra la estimación sobre la disminución de superficie necesaria para los sistemas tradicionales de macrofitas en flotación y para el sistema optimizado de bancales industrializables. Teniendo en cuenta un incremento de la superficie necesaria del $20 \%$, para incluir zonas transitables en el caso de bancales industrializados, se consigue una optimización del espacio casi cinco veces inferior a los modelos extensivos (tabla 3).

\section{Tabla 3}

Comparativa entre superficie requerida en sistemas de FMF extensivos y en la propuesta de optimización del recorrido

Filtro macrofitas flotación extensivos (4)

\begin{tabular}{|l|r|}
\hline Habitantes equivalentes totales & 1.680 \\
\hline $\mathrm{m}^{2} /$ habitante equivalente & 5 \\
\hline Superficie requerida total & $\mathbf{8 . 4 0 0}$ \\
\hline \multicolumn{2}{|c|}{} \\
\hline \multicolumn{2}{|c|}{ Optimización de recorrido de aguas grises } \\
\hline Volumen total agua depurada $\left(\mathrm{m}^{3}\right)$ & 156,2 \\
\hline Altura bancales industrializados $(\mathrm{m})$ & 0,5 \\
\hline Superficie requerida diaria $\left(\mathrm{m}^{2}\right)$ & 312,5 \\
\hline Pérdidas por evaporación $(\%)$ & $30 \%$ \\
\hline Periodo fitodepuración (días) & 7 \\
\hline Superficie requerida total & $1.531,2$ \\
\hline Total superficie (incl.circulación) $\left(\mathrm{m}^{2}\right)$ & $\mathbf{1 . 8 4 0 , 0}$ \\
\hline
\end{tabular}

Fuente: Elaboración propia.

\subsection{Ahorros de consumo}

Se han estudiado diferentes casuísticas, para cuantificar el impacto de la reuitilización de las aguas grises, en función de tres parámetros principales: la procedencia de las aguas a depurar, la incorporación de sistemas de fitodepuración para su tratamiento y la complementación con medidas correctoras de reducción de consumo. Respecto a estas últimas se ha diferenciado entre la sustitución única de inodoros por otros de doble descarga de tanque de 3 y 6 litros y la complementación con medidas
Tabla 2

Características principales de las especies seleccionadas para el proyecto

\begin{tabular}{|c|c|c|}
\hline Imagen & Especie vegetal & Condiciones climáticas (4) \\
\hline 8 & $\begin{array}{l}\text { Phragmites australis } \\
\text { (carrizo) } \\
\text { Familia: Poaceae }\end{array}$ & $\begin{array}{l}\text {-clima continental } \\
\text {-temperatura óptima } 12-23^{\circ} \mathrm{C} \\
\text {-sobrevive temp. extremas }-5^{\circ} \mathrm{C}\end{array}$ \\
\hline 9 & $\begin{array}{l}\text { Typha latifolia L. } \\
\text { (enea) } \\
\text { Familia: Typhaceae }\end{array}$ & $\begin{array}{l}\text {-clima mediterráneo semiárido } \\
\text {-temperatura óptima de } 20^{\circ} \mathrm{C}\end{array}$ \\
\hline $1:(y)$ & $\begin{array}{l}\text { Scirpus Holoschoenus } \\
\text { (junco de bolas) } \\
\text { Familia: Cyperaceae }\end{array}$ & $\begin{array}{l}\text {-clima mediterráneo templado soleado } \\
\text {-temperatura óptimo } 16-27^{\circ} \mathrm{C}\end{array}$ \\
\hline
\end{tabular}

Fuente: Tabla de Elaboración propia.

reductoras en grifería y aparatos de menor demanda de agua.

A continuación se muestran las principales combinaciones estudiadas (tablas 4 y 5), en las que se establece como reutilización prioritaria la descarga de inodoros y se estudia la posibilidad de emplear el agua depurada restante en riego por goteo subterráneo en parques y en baldeo de calles.

Tabla 4

Estimación de reducción de consumos

Agua de duchas/bañera, bidet y lavabo

Hipótesis A_solo fitodepuración

Posibilidad reutilización media diaria

\begin{tabular}{|l|l|}
\hline Total habitantes equivalentes & 1.680 \\
\hline
\end{tabular}

\begin{tabular}{|l|l|}
\hline Producción aguas grises (l/hab.eq) & 60 \\
\hline
\end{tabular}

\begin{tabular}{|l|r|}
\hline Total litros & 100.800 \\
\hline Total depurada (litros incl. pérdidas 30\%) & 70.560 \\
\hline
\end{tabular}

\begin{tabular}{|l|r|}
\hline Descarga de inodoros (l/hab.eq) & 45 \\
\hline
\end{tabular}

\begin{tabular}{|l|r|}
\hline Total litros requeridos & 75.600 \\
\hline Aporte agua necesario extra (I) & -5.040 \\
\hline
\end{tabular}

Hipótesis B_ incluyendo recambio inodoros de bajo consumo

Posibilidad reutilización media diaria

\begin{tabular}{|l|l}
\hline Total habitantes equivalentes & 1.680
\end{tabular}

\begin{tabular}{|l|r}
\hline Producción aguas grises (l/hab.eq) & 60 \\
\hline Total litros & 100.800 \\
\hline
\end{tabular}

\begin{tabular}{|l|l}
\hline Total depurada (litros incl. pérdidas 30\%) & 70.560 \\
\hline
\end{tabular}

\begin{tabular}{|l|r}
\hline Descarga de inodoros (l/hab.eq) & 16 \\
\hline Total litros requeridos & 26.880 \\
\hline
\end{tabular}

\begin{tabular}{|l|l|}
\hline Reutilización sobrante en riego (I) & 43.680 \\
\hline
\end{tabular}

Hipótesis $C_{-}$incluyendo medidas correctoras globales en vivienda

Posibilidad reutilización media diaria

\begin{tabular}{|l|l|}
\hline Total habitantes equivalentes & 1.680 \\
\hline
\end{tabular}

\begin{tabular}{|l|r}
\hline Producción aguas grises (l/hab.eq) & 46 \\
\hline
\end{tabular}

\begin{tabular}{|l|l|}
\hline Total litros & 77.280 \\
\hline
\end{tabular}

\begin{tabular}{|l|l|}
\hline Total depurada (litros incl. pérdidas 30\%) & 54.096 \\
\hline
\end{tabular}

\begin{tabular}{|l|r}
\hline Descarga de inodoros (l/hab.eq) & 16
\end{tabular}

\begin{tabular}{|l|l|}
\hline Total litros requeridos & 26.880 \\
\hline Reutilización sobrante
\end{tabular}

\begin{tabular}{|l|l|}
\hline Reutilización sobrante en riego (l) & 27.216 \\
\hline
\end{tabular}

Fuente: Elaboración propia. 
De la comparativa se deduce que en el caso de recogida única de agua de duchas, bañera, bidet y lavabo, sin realizar medidas de reducción de consumo, el agua tratada no llegaría a cumplir la demanda total de descarga de inodoros. Sin embargo, en el resto de casuísticas planteadas, la cantidad de agua es suficiente para cubrir toda la demanda en inodoros y todavía sobraría un porcentaje siempre superior al 50\% del agua depurada, para ser utilizada en riego o baldeo de calles cercanas.

Respecto a la aplicación de medidas correctoras de reducción de consumo, éstas afectan directamente al volumen de aguas grises producidas, aunque también se reduce la demanda por parte de los inodoros de bajo consumo, por lo que se estabiliza la relación entre aguas grises generadas y reutilizadas.

De las estrategias estudiadas, la hipótesis C en la que se incluye el agua producida en lavadoras, es la más favorable desde la valoración de consumos; aunque existe la problemática de que todos los vecinos deberían utilizar jabones orgánicos que no dañasen el crecimiento de las plantaciones.

Tabla 5

Estimación de reducción de consumos

\begin{tabular}{|c|c|}
\hline \multicolumn{2}{|c|}{ Agua duchas, bidet, lavabo y lavadora } \\
\hline \multicolumn{2}{|l|}{ Hipótesis A_solo fitodepuración } \\
\hline \multicolumn{2}{|l|}{ Posibilidad reutilización media diaria } \\
\hline Total habitantes equivalentes & 1.680 \\
\hline Producción aguas grises (I/hab.eq) & 93 \\
\hline Total litros & 156.240 \\
\hline Total depurada (litros incl. pérdidas 30\%) & 109.368 \\
\hline Descarga de inodoros (l/hab.eq) & 45 \\
\hline Total litros requeridos & 75.600 \\
\hline Reutilización sobrante en riego (l) & 33.768 \\
\hline \multicolumn{2}{|c|}{$\begin{array}{l}\text { Hipótesis } B_{-} \text {incluyendo recambio inodoros de } \\
\text { bajo consumo }\end{array}$} \\
\hline \multicolumn{2}{|l|}{ Posibilidad reutilización media diaria } \\
\hline Total habitantes equivalentes & 1.680 \\
\hline Producción aguas grises (I/hab.eq) & 93 \\
\hline Total litros & 156.240 \\
\hline Total depurada (litros incl. pérdidas 30\%) & 109.368 \\
\hline Descarga de inodoros (l/hab.eq) & 16 \\
\hline Total litros requeridos & 26.880 \\
\hline Reutilización sobrante en riego (l) & 82.488 \\
\hline \multicolumn{2}{|c|}{$\begin{array}{l}\text { Hipótesis } C_{-} \text {incluyendo medidas correctoras } \\
\text { globales en vivienda }\end{array}$} \\
\hline \multicolumn{2}{|l|}{ Posibilidad reutilización media diaria } \\
\hline Total habitantes equivalentes & 1.680 \\
\hline Producción aguas grises (l/hab.eq) & 64 \\
\hline Total litros & 107.520 \\
\hline Total depurada (litros incl. pérdidas 30\%) & 75.264 \\
\hline Descarga de inodoros (l/hab.eq) & 16 \\
\hline Total litros requeridos & 26.880 \\
\hline Reutilización sobrante en riego (l) & 48.384 \\
\hline
\end{tabular}

Fuente: Elaboración propia.

\section{DISCUSIÓN}

En base a las estimaciones de consumo realizadas, se ha procedido a cuantificar los beneficios de cada una de las propuestas; tanto en relación con las diferentes estrategias planteadas, como en los porcentajes de ahorro respecto a la aplicación únicamente de medidas correctoras de consumo (tablas 6 y 7).

A continuación se exponen las estimaciones de ahorro correspondientes a cada una de las combinaciones planteada; donde se observa que es posible alcanzar ahorros de hasta un $59 \%$ respecto al consumo actual de agua potable.

\section{Tabla 6}

Porcentajes de reducción de consumo estimados

\section{Agua de duchas/bañera, bidet y lavabo}

\section{Hipótesis A_solo fitodepuración}

- Las aguas grises producidas no son suficientes para cubrir el $100 \%$ de la demanda en descarga de inodoros. Sin embargo, solamente es necesario aportar un $7 \%$ para cubrir el consumo.

- El sistema ahorra un $25 \%$ respecto al consumo actual de agua potable.

Hipótesis B_incluyendo recambio inodoros de

bajo consumo

- Se estima que la estratega puede ahorrar hasta un $34 \%$ respecto al consumo actual de agua potable.

- La estrategia combinada de fitodepuración y recambio de inodoros por otros de bajo consumo, consigue ahorros de hasta un $27 \%$, respecto a únicamente reemplazar los inodoros.

Hipótesis C incluyendo medidas correctoras globales en vivienda

- Se estima que la estratega puede ahorrar hasta un $45 \%$ respecto al consumo actual de agua potable.

- La estrategia combinada de fitodepuración y medidas correctoras globales en vivienda, consigue ahorros de hasta un $32 \%$, respecto a únicamente utilizar medidas correctoras de consumo.

Fuente: Elaboración propia.

En conclusión, además de los ahorros directos de consumo de agua potable que se podrían alcanzar mediante la aplicación de estas estrategias, la incorporación de sistemas de tratamiento de aguas grises al ciclo de gestión de agua urbana, puede aportar significativas ventajas respecto al modelo hidrológico urbano actual, pudiendo alcanzar disminuciones de más de un $50 \%$ en el volumen recibido por las E.D.A.R. convencionales.

Además, la industrialización de los bancales aporta beneficios económicos, tanto respecto a los procesos de construcción y deconstrucción como a las ventajas de la producción en 
serie de sistemas modulares. De este modo, se ha estimado que la construcción del prototipo para la cubierta de una vivienda unifamiliar con 5 habitantes equivalentes puede suponer un gasto de 1.200 euros por habitante, incluyendo la instalación y la construcción.

\section{Tabla 7}

Porcentajes de reducción de consumo estimados

Agua de duchas, bidet, lavabo y lavadora Hipótesis A_solo fitodepuración

- El sistema ahorra un $39 \%$ respecto al consumo actual de agua potable.

Hipótesis $B_{-}$incluyendo recambio inodoros de bajo consumo

- Se estima que la estratega puede ahorrar hasta un $43 \%$ respecto al consumo actual de agua potable.

- La estrategia combinada de fitodepuración y recambio de inodoros por otros de bajo consumo, consigue ahorros de hasta un $48 \%$, respecto a únicamente reemplazar los inodoros.

Hipótesis $C_{-}$incluyendo medidas correctoras globales en vivienda

- Se estima que la estratega puede ahorrar hasta un $59 \%$ respecto al consumo actual de agua potable.

- La estrategia combinada de fitodepuración y medidas correctoras globales en vivienda, consigue ahorros de hasta un $67 \%$, respecto a únicamente utilizar medidas correctoras de consumo.

Fuente: Elaboración propia.

Sin embargo, su uso en distritos centralizados disminuirá considerablemente el precio por habitante, hasta en un $40 \%$, al disminuir el trazado de redes y optimizar las dimensiones de bancales.
Por ello, los sistemas industrializables de fitodepuración presentan un gran potencial de incorporación en las grandes superficies infrautilizadas que se generaron en los desarrollos urbanos de los años 70 y 80 permitiendo no solo la optimización de la gestión del ciclo de agua, sino aportando nuevas condiciones de calidad visual y ambiental a los distritos donde se aplica, y alterando positivamente el paisaje urbano (figura 9).
9. Integración urbana del sistema de en cubierta. Elaboración propia.

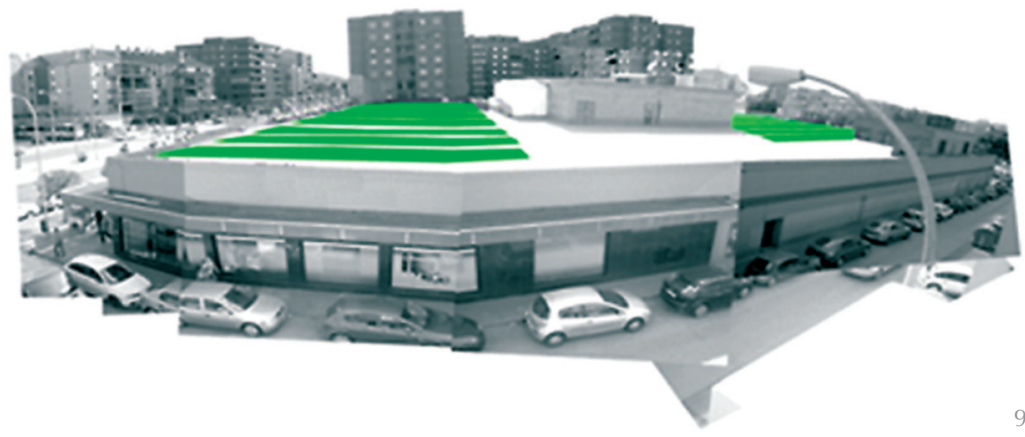

\section{AGRADECIMIENTOS}

El proyecto ha sido desarrollado dentro del Proyecto Estratégico y Singular INVISO (Industrialización de Viviendas Sostenibles), financiado por el Ministerio de Ciencia e Innovación del Gobierno de España.

Los autores expresan su agradecimiento al biólogo Óscar Domínguez y PROSOJARD S.L por sus importantes contribuciones.

\section{BIBLIOGRAFÍA}

(1) Jefferson, B.: "Grey Water characterisation and its impact on the selection and operation of technologies for urban reuse". Water Science and Technology, vol. 50, n 2 (2004), pp. 157-164.

(2) Nolde, E.: "Greywater reuse systems for toilet flushing in multi-storey buildings-over ten years experience in Berlin". Urban Water, vol. 1, n 1 (1999), pp. 275-284.

(3) Butler, D. et al.: "Characterising the quantity and quality of domestic wastewater inflows". Water Science and Technology, vol. 31, nº 7 (1995), pp. 13-24.

(4) Fernández, J.: Filtros de macrofitas en flotación, Ayto. de Murcia, Murcia, 2005

(5) Pucci, B.: Linee Guida per la progettazione e gestione di zone umide artificiali per la depurazione dei reflui, Italian Environmental Protection Agency, 2005.

(6) Moshiri, G.: A. Constructed Wetlands for Water Quality Improvement, CRC Press, Florida, 1993.

(7) Knight, R. L.: Wetlands for wastewater treatment data base, Intermational Conference Wetland Systems in Water Pollution Control, Sydney, 1992. 